\title{
Chronic obstructive pulmonary disease as a systemic disease: an epidemiological perspective
}

\author{
H. Andreassen, J. Vestbo
}

\begin{abstract}
Chronic obstructive pulmonary disease as a systemic disease: an epidemiological perspective. H. Andreassen, J. Vestbo. (C) ERS Journals Ltd 2003.

ABSTRACT: Chronic obstructive pulmonary disease (COPD) has been increasingly recognised as a systemic disease. The hormonal, metabolic and musculoskeletal implications of the generalised processes involving oxidative stress, inflammatory mediators, cytokines, and endocrine hormones have only begun to be understood.

Only a few studies have looked into the epidemiology of inflammatory markers in patients with chronic obstructive pulmonary disease. Common extrapulmonary effects of chronic obstructive pulmonary disease include skeletal muscle dysfunction, wasting and osteoporosis. The resulting effects of a systemic inflammation can be measured at specific extrapulmonary organs such as skeletal muscle or in more general terms using body composition, body weight or derived measures, and only a few studies have set the parameters in an epidemiological context. Nevertheless, these studies indicate an association between inflammatory markers and forced expiratory volume in one second not only in subjects with severe chronic obstructive pulmonary disease. Also, it is increasingly clear that systemic markers in chronic obstructive pulmonary disease have important effects on prognosis.

Eur Respir J 2003; 22: Suppl. 46, 2s-4s.
\end{abstract}

Dept of Respiratory Medicine, Hvidovre University Hospital, Hvidovre, Denmark.

Correspondence: H. Andreassen, Dept of Respiratory Medicine 221, Hvidovre University Hospital, Kettegaard Alle 30, DK-2650 Hvidovre, Denmark

Fax: 4536323716

E-mail: helleandreassen@ofir.dk

Keywords: Body mass index chronic obstructive pulmonary disease epidemiology muscle dysfunction weight loss

Received and accepted June 302003
Chronic obstructive pulmonary disease (COPD) has been classified as "a disease state characterised by airflow limitation that is not fully reversible. The airflow limitation is usually both progressive and associated with an abnormal inflammatory response of the lungs to noxious particles or gases" [1]. Although not mentioned in the definition it is clear to clinicians that apart from the deleterious effects on the lungs, the disease in its end-stage has generalised effects and can be considered a systemic disease with metabolic and musculoskeletal implications [2]. Common extrapulmonary effects of COPD include skeletal muscle dysfunction, wasting and osteoporosis [3].

Epidemiology studies the distribution of disease in populations, and in COPD epidemiology has been important in describing the natural course of the disease. Many of the extrapulmonary or systemic effects can potentially be studied using epidemiological methods and this would be important for the proper understanding of COPD. However, epidemiological data on these subjects are scarce and can be divided into studies on markers of systemic inflammation and studies on prognosis according to markers of a systemic effect.

The following article will describe the present epidemiological knowledge on systemic effects of COPD and try to outline the areas where progress can be expected.

\section{Markers of systemic inflammation in chronic obstructive pulmonary disease}

The primary culprit leading to the development of COPD is tobacco. Smoking is thought to create an imbalance between oxidative and antioxidative factors, locally in the lungs, causing oxidative stress, which has been hypothesised as probably the most important pre-inflammatory event in the pathogenesis of COPD. Markers of oxidative stress and the resulting inflammation in smokers either with COPD or presumably at risk of the disease, include nitrogenoxid, interleukin (IL)-8, tumour necrosis factor- $\alpha(\mathrm{TNF}-\alpha)$, hydrogen peroxide, and isoprostanes, which can be measured in induced sputum, blood, expired air or bronchoalveolar lavage fluid $[4,5]$. No epidemiological studies have so far included these specific measures. Potentially they could indicate early changes or even act as markers of susceptibility in subjects with normal lung function. The use of both exhaled markers and markers measured systemically in blood samples could provide a means of measuring the extent of systemic involvement at different stages of the disease. Hopefully, measures from condensated breath could provide a means for implementation of monitoring inflammation in COPD, also in epidemiological surveys. At present, these novel techniques need to be refined in order to make them both cheaper and easier/less time-consuming to apply.

In established COPD, a number of nonspecific markers of ongoing inflammation are available. The neutrophil leukocyte releases proteinases capable of degrading most components of the extracellular matrix, an event that is normally inhibited by antiproteinases such as $\alpha_{1}$-antitrypsin $\left(\alpha_{1}\right.$-AT). Neutrophils are increased in the airways of smokers [6] and patients with COPD [7] and can be assessed in sputum and induced sputum from patients with COPD $[8,9]$. Data from a small study in smokers and exsmokers indicate that an increased number of neutrophils in the sputum is associated with an accelerated decline in lung function [8]; this association has also been reported among smokers in an occupational cohort [10]. In most population studies, however, neutrophils will provide a too crude marker of generalised inflammation, not least because of the large intra-individual variation in leukocyte count. C-reactive protein (CRP) is an acute phase reactant protein measured in plasma, synthesised by the liver in 
response to inflammation. CRP is elevated in patients with stable COPD, regardless of stage [11-13], and in patients the treatment of exacerbations is associated with a decline in CRP [11]. Fibrinogen is synthesised by hepatocytes and is an acute phase reactant and a blood clotting factor, released into circulation in response to the cytokine IL-6, which is produced by macrophages and airway epithelium. Elevated levels of fibrinogen have been reported in patients with stable COPD and in acute exacerbations [14, 15]. IL-6 is the primary regulating cytokine of the acute phase reactant $\alpha_{1}$-AT which is also considered the major inhibitor of neutrophil elastase in the lower respiratory system. Apart from its well-recognised role as a hereditary risk factor for emphysema, measures of $\alpha_{1}$-AT can serve as measures of ongoing inflammation in COPD.

A few studies have been published, concerning the connection between acute phase reactants and pulmonary function. DAHL et al. [16] reported on the association between fibrinogen and forced expiratory volume in one second (FEV1) in 8,955 subjects from the general population. There was an inverse relationship between FEV1 and fibrinogen. Smokers with plasma fibrinogen in the upper and middle tertiles had a $7 \%$ and $2 \%$ lower FEV1 \% predicted than smokers with fibrinogen in the lower tertile. Correspondingly, nonsmokers with plasma fibrinogen in the upper tertile had a $6 \%$ lower FEV1\% pred than nonsmokers with plasma fibrinogen in the lower tertile. Smokers with fibrinogen in the upper tertile had an excess annual decline in FEV1 of $6 \mathrm{~mL} \cdot \mathrm{yr}^{-1}$ compared with smokers with fibrinogen in the lower tertile. Nonsmokers with plasma fibrinogen in the upper tertile had an excess annual decline in FEV1 of $4 \mathrm{~mL} \cdot \mathrm{yr}^{-1}$.

Single-breath diffusing capacity of carbon monoxide $(T \mathrm{~L}, \mathrm{CO})$, a marker of gas diffusion in the lungs, is reduced in $\alpha_{1}$-AT deficient patients [17]. WELLE et al. [18] examined the relationship between TL,CO and serum levels of $\alpha_{1}$-AT and calprotectin, a plasma marker for neutrophil activation, in a stratified sample $(n=1,121)$ from the Norwegian population. An inverse relationship was found between $\alpha_{1}$-AT and FEV1 \% pred, and between $\alpha_{1}$-AT and TL,CO, though only significant in females. The relationship persisted after excluding patients with known asthma or COPD. This suggests to the current authors that an ongoing inflammatory process results in injury in the alveolar space, leading to emphysema.

Future epidemiological studies could focus on describing the relationship between markers of inflammation and subgroups of COPD; the markers can be measured in a larger set-up, and the use of materials from bio-banks might be considered. However, before investing too much in evaluating large series of paraclinical measures, an effort should probably be made to try to find better parameters to subclassify patients with COPD according to the mechanism responsible for airflow limitation.

Resulting effects of a systemic inflammation can either be measured in specific extrapulmonary organs such as skeletal muscle or in more general terms using body composition, body weight or derived measures. Skeletal muscle dysfunction is a recognised problem in chronic conditions like COPD. The mechanisms contributing to muscle dysfunction are deconditioning, malnutrition, skeletal muscle myopathy and low levels of circulating anabolic hormones [19]. Based on data from a community population in subjects $>50 \mathrm{yrs}$, COPD and use of oral corticosteroids led to identification of osteoporosis in close to $60 \%$ [20]. Contributing factors leading to reduced bone mineral density in COPD are smoking, vitamin D deficiency, reduced body mass index (BMI), hypogonadism, immobility and the use of glucocorticoids [21].

Weight loss is caused by energy expenditure not balanced by dietary intake. Disproportionate muscle wasting has been described in chronic conditions, as in COPD, and unexplained weight loss is common in patients with COPD [22]. A clinical study has shown that measuring mid-thigh muscle cross-sectional area is a better predictor of mortality than BMI in patients with COPD, indicating that the loss of muscle has a greater implication for prognosis than loss of other compartments [23]. The inflammatory cytokine TNF- $\alpha$ (cachexin) is associated with accelerated metabolism and protein turnover and is elevated in weight-losing patients with COPD $[24,25]$. The gene product of the obesity gene leptin is reduced in underweight patients with COPD as compared to healthy controls, suggesting a role for circulating leptin in weight loss in the patients [26].

None of these more specific descriptors of altered metabolism have been examined in larger unselected population samples; in fact, little data have been published on distribution of body weight or body composition in relation to progression of COPD. From unpublished data from the Copenhagen City Heart Study it can be seen that the proportion of patients with low BMI, defined as BMI $<20 \mathrm{~kg} \cdot \mathrm{m}^{-2}$ increases with increasing severity of COPD. However, even in subjects with mild COPD defined as FEV1 $>70 \%$ pred $3.5 \%$ of males and $12.5 \%$ of females had low BMI. BMI is easily available in almost all surveys and body composition can be estimated with reasonable certainty using body impedance measures which can be applied in almost all epidemiological surveys. Whereas the use of impedance measuring lean body mass is already feasible in epidemiology, future epidemiological studies could also focus on using dual energy X-ray absorptiometry (DEXA) scanning in describing body composition, a method which is performed increasingly quickly. It thus seems obvious that epidemiology should be able to describe body weight and body composition in much more detail.

\section{Prognostic studies using markers of systemic effects in chronic obstructive pulmonary disease}

An association between body weight and COPD has been recognised for many years, and an inverse relationship between weight loss or BMI and survival in patients with COPD has been reported in prospective survival studies [27-29].

LANDBO et al. [30] conducted a prospective study on mortality in subjects with COPD $(n=2,132)$ in a randomly selected sample from the population of Copenhagen. The study showed an effect of BMI on COPD mortality independent of sex and lung function. Poor prognosis was clearly related to being underweight, defined as BMI $<20 \mathrm{~kg} \cdot \mathrm{m}^{-2}$. The association between BMI and mortality varied with severity of COPD and was strongest in subjects with severe COPD defined as FEV $1<50 \%$ pred. In this group there was an almost linear relationship between BMI and COPD mortality which differs from the usual J- or U-shaped relationship between BMI and mortality. This indicates that the characterisation of "underweight", "normal weight", "overweight", and "obese" based on BMI should probably use other cut-off points for COPD patients than for subjects without lung disease, and that underweight is more important than overweight in severe COPD. Using the same study base, PRESCOTT et al. [31] examined the relationship between changes in weight and mortality in subjects with COPD $(n=1,612)$. The population sample was followed prospectively and the prognostic value of weight change over 5 yrs was examined. The study showed that weight loss is an independent risk factor for all-cause mortality in patients with COPD and that weight gain seems to have a protective effect in normal and underweight patients with severe COPD defined as FEV $1<50 \%$ pred, as shown in fig. 1. These findings support the preconclusions of the previous Copenhagen study and shows that previously reported findings by SCHOLS et al. [28] from a rehabilitation patient cohort can be applied to COPD patients in general. 


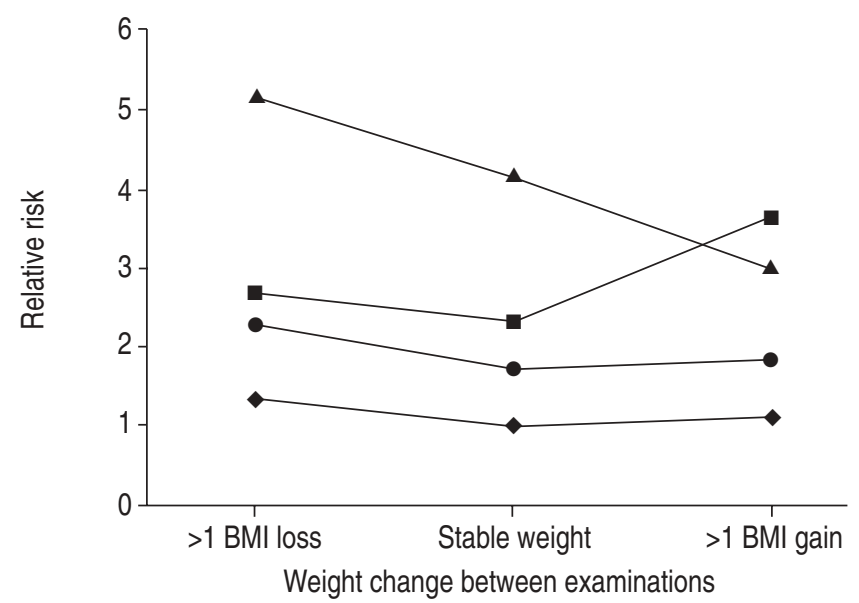

Fig. 1.-All-cause mortality by weight change in subjects with no/mild chronic obstructive pulmonary disease (COPD), moderate COPD and severe COPD. Subjects with no/mild COPD with stable weight were used for reference. $\boldsymbol{\Delta}$ : severe COPD body mass index $(\mathrm{BMI})<25$; $\boldsymbol{\square}$ severe COPD BMI >25; ๑: moderate COPD; $\bullet$ : no/mild COPD. Reproduced with permission from [31].

Hopefully, future epidemiological studies can further increase knowledge on prognosis by combining prospectively sampled data on both detailed and crude measures of systemic inflammation as well as data on body weight and body composition with data on disease progression and eventually death.

\section{References}

1. World Health Organization. The GOLD global strategy for the management and prevention of COPD. www.goldcopd. com. Date accessed: September 2002.

2. Wouters EFM, Creutzberg EC, Schols AMWJ. Systemic effects in COPD. Chest 2002; 121: 127s-130s.

3. Gross NJ. Extrapulmonary effects of chronic obstructive pulmonary disease. Curr Opin Pulm Med 2001; 7: 84-92.

4. Rahman I, MacNee W. Role of oxidants/antioxidants in smoking-induced lung diseases. Free Radical Biology and Med 1996; 21: 669-681.

5. MacNee W. Oxidants/antioxidants and COPD. Chest 2000; 117: $303 \mathrm{~s}-317 \mathrm{~s}$.

6. Hunninghake GW, Crystal RG. Cigarette smoking and lung destruction. Accumulation of neutrophils in the lungs of cigarette smokers. Am Rev Respir Dis 1993; 128: 833-838.

7. Confalonieri M, Mainardi EM, Della Porta R, et al. Inhaled corticosteroids reduce neutrophilic bronchial inflammation in patients with chronic obstructive pulmonary disease. Thorax 1998; 53: 583-585.

8. Stanescu D, Sanna A, Veriter C, et al. Airways obstruction, chronic expectoration, and rapid decline of FEV1 in smokers are associated with increased levels of sputum neutrophils. Thorax 1996; 51: 267-271.

9. Keatings VM, Barnes PJ. Granulocyte activation markers in induced sputum: comparison between chronic obstructive pulmonary disease, asthma, and normal subjects. $A m J$ Respir Crit Care Med 1997; 155: 449-453.

10. Chan-Yeung M, Abboud R, Buncio AD, Vedal S. Peripheral leukocyte count and longitudinal decline in lung function. Thorax 1988; 43: 462-466.

11. Dentener MA, Creuzberg EC, Schols AMWJ, et al. Systemic anti-inflammatory mediators in COPD: increase in soluble interleukin 1 receptor II during treatment of exacerbations. Thorax 2001; 56: 721-726.

12. Schols AM, Buurman WA, Staal van den Brekel AJ, Dentener MA, Wouters EF. Evidence for a relation between metabolic derangements and increased levels of inflammatory mediators in a subgroup of patients with chronic obstructive pulmonary disease. Thorax 1996; 51: 819-824.

13. Yasuda N, Gotoh K, Minatoguchi S, et al. An increase of soluble Fas, an inhibitor of apoptosis, associated with progression of COPD. Respir Med 1998; 92: 993-999.

14. Wedzicha JA, Seemungal TA, MacCallum PK, et al. Acute excercabations of chronic obstructive pulmonary disease are accompanied by elevations of plasma fubrinogen and serum IL-6 levels. Thromb Haemost 2000; 84: 210-215.

15. Seemungal T, Harper-Owen R, Bhowmik A, et al. Respiratory viruses, symptoms, and inflammatory markers in acute exacerbations and stable chronic obstructive pulmonary disease. Am J Respir Crit Care Med 2001; 164: 1618-1623.

16. Dahl M, Tybjærg-Hansen A, Vestbo J, Lange P, Nordestgaard BG. Elevated plasma fibrinogen associated with reduced pulmonary function and increased risk of chronic obstructive pulmonary disease. Am J Respir Crit Care Med 2002; 164: 1008-1011.

17. Schwaiblmair M, Vogelmeier C, Fruhmann G. Long-term augmentation therapy in twenty patients with severe alpha-1antitrypsin deficiency - three year follow up. Respiration 1997; 64: 10-15.

18. Welle I, Bakke PS, Eide GE, Fagerhol MK, Omenaas E, Gulsvik A. Increased circulating levels of alpha1-antitrypsin and calprotectin are associated with reduced gas diffusion in the lungs. Eur Respir $J$ 2001; 17: 1105-1111.

19. Casaburi R. Skeletal muscle dysfunction in chronic obstructive pulmonary disease. Med Sci Sports Excerc 2001; 33: S662-S670.

20. Biskobing DM. COPD and osteoporosis. Chest 2002; 12 609-620.

21. Walsch LJ, Lewis SA, Wong CA, et al. The impact of oral corticosteroid use on bone mineral density and vertebral fracture. Am J Respir Crit Care Med 2002; 166: 691-695.

22. Schols AMWJ, Soeters AMC, Dingemans R, Mostert PJ, Frantzen, Wouters EFM. Prevalence and characteristics of nutritional depletion in patients with stable COPD eligible for pulmonary rehabilitation. Am J Respir Crit Care Med 1993; 147: 1151-1156.

23. Marquis K, Debigare R, Lacasse Y, et al. Midthigh muscle cross-sectional area is a better predictor of mortality than body mass index in patients with chronic obstructive pulmonary disease. Am J Respir Crit Care Med 2002; 166: 809-813.

24. Di Francia M, Barbier D, Mege JL, Orehek J. Tumor necrosis factor-alpha levels and weight loss in chronic obstructive pulmonary disease. Am J Respir Crit Care Med 1994; 150: $1453-1455$.

25. De Godoy I, Donahoe M, Calhoun WJ, Mancino J, Rogers RM. Elevated TNF-alpha production by peripheral blood monocytes of weight-losing COPD patients. Am J Respir Crit Care Med 1996; 153: 633-637.

26. Takabatake N, Nakamura H, Abe S, et al. Circulating leptin in patients with chronic obstructive pulmonary disease. $\mathrm{Am}$ $J$ Respir Crit Care Med 1999; 159: 1215-1219.

27. Wilson DO, Rogers RM, Wright EC, Anthonisen NR. Body weight in chronic obstructive pulmonary disease. The National Institutes of Health Intermittent Positive-Pressure Breathing Trial. Am Rev Respir Dis 1989; 139: 1435-1438.

28. Schols AMWJ, Slangen J, Volovics L, Wouters EFM. Weight loss is a reversible factor in the prognosis of chronic obstructive pulmonary disease. Am J Respir Crit Care Med 1998; 157: 1791-1797.

29. Gray-Donald K, Gibbons L, Shapiro SH, Macklem PT, Martin JG. Nutritional status and mortality in chronic obstructive pulmonary disease. Am J Respir Crit Care Med 1996; 153: 961-966.

30. Landbo C, Prescott E, Lange P, Vestbo J, Almdal TP. Prognostic value of nutritional status in chronic obstructive pulmonary disease. Am J Respir Crit Care Med 1999; 160: 1856-1861.

31. Prescott E, Almdal T, Mikkelsen KL, Tofteng CL, Vestbo J, Lange P. Prognostic value of weight change in chronic obstructive pulmonary disease: results from the Copenhagen City Heart Study. Eur Respir J 2002; 20: 539-544. 